\title{
55. An Experimental Study of Stereotaxic Lesion on the Cat Brain by Focused Ultrasound
}

\author{
Minoru Ishir, Tatsuo Takeuchi, Hirotoshi NonaKa, K. Takeuchi \\ and M. TAKAGAKI \\ Dept. of Surgery, Juntendo University School of Medicine
}

The concave barium titanate focusing irradiator has been used in our laboratory. Newly, the $x$-ray control, stereotaxic operation table, focusing irradiator were improved. Cat brains were irradiated at frequency of $1 \mathrm{Mc} / \mathrm{sec}$; the peak intensity at the focus was $1400 \mathrm{~W} / \mathrm{cm}^{2}$. The present study was the report that neuropathological effects of irradiation with focused ultrasound were observed the lesion of the cat brain. The lesions were followed 3 hours to 3 months after irradiation. Especially, nerve cells, myelyn sheaths, blood vessels and glia cells were studied histopathologically. Lesions could be made in the white matter or grey matter. These examples gave the result that the grey matter was less susceptible than the white matter to the destruction of ulrasound. The sharply linear lesion could be produced at the boundary between the white matter and the grey matter. Furthermore, destruction of the hypophysis of the cat could be made by focused ultrasound.

Recently, the present writers carried out a study whether it is possible to detect the focused lesion in the cat brain tissue by means of ultrasonic echo method. Focused ultrasound of which maximum intensity was $1.4 \mathrm{KW} / \mathrm{cm}^{2}$, irradiated through the parietal dura mater into the cat brain. At the same time, echo detection was tried from the focused region by using an ultrasonic detecting transducer, $10 \mathrm{~mm}$. in diameter and frequency of 5 megacycle which was placed on the dura mater through temporal burr hole. Immediately after the irradiation of focused ultrasound 5 seconds, there was able to detect an echo reflected from the focused region. The echo intensity diminished with the lapse of time and the echo was completely disappeared in nearly three minutes after irradiation.

\section{Induced Exacerbation of Parkinsonian Rigidity}

\section{-Clinical and Electromyographical Investigation-}

\author{
Keizo Matsumoto
}

2nd Dept. of Surgery, Osaka University Medical School

Recent increasing interest in basal ganglia surgery for tremor and rigidity 